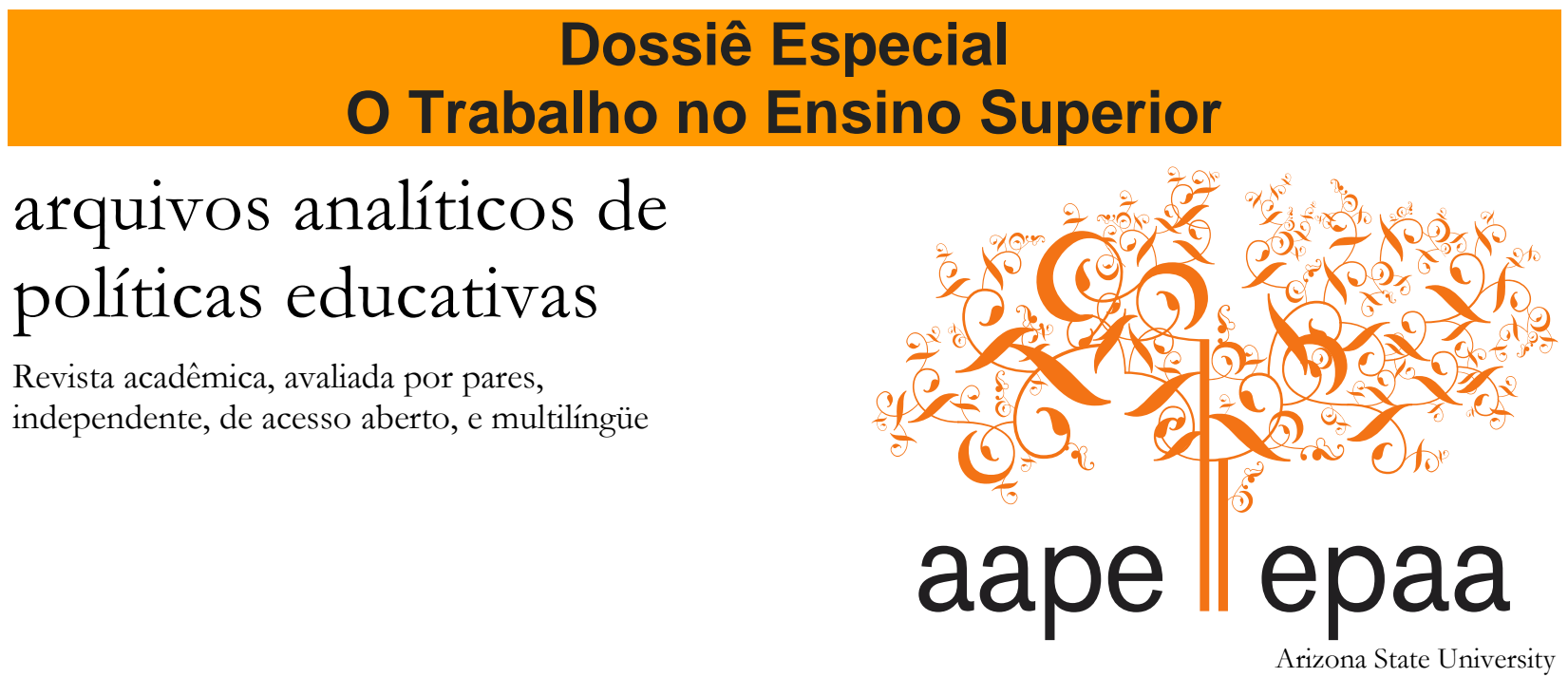

Volume 28 Número $11 \quad 20$ de janeiro de 2020

ISSN 1068-2341

\title{
Assédio Moral na Pós-Graduação: As Consequências Vivenciadas por Docentes e Discentes de uma Universidade Estadual Brasileira
}

\author{
Thiago Soares Nunes \\ ¿\% \\ Eliana Marcia Martins Fittipaldi Torga \\ Centro Universitário Una \\ Brasil
}

Citação: Nunes, T. S., \& Torga, E. M. M. F. (2020). Assédio moral na pós-graduação: As consequências vivenciadas por docentes e discentes de uma Universidade Estadual brasileira. Arquivos Analiticos de Politicas Educativas, 28(11). https://doi.org/10.14507/epaa.28.4883 Este artigo faz parte do dossiê especial, O trabalho na educação superior, editada por Deise Mancebo, Kátia Maria Teixeira Santorum, Denise Bessa Léda, e Carla Vaz dos Santos Ribeiro.

Resumo: A Pós-Graduação apresenta um contexto fértil para a ocorrência de assédio moral, pois tem, nas suas práticas, cobranças e pressões intensas, busca frequente pelo produtivismo, alta competitividade e vaidade. Por isso, as consequências desse ambiente exigente podem ser ainda mais severas, afetando a saúde, o trabalho, os estudos e a vida privada do profissional. Diante do que foi exposto, este artigo tem como objetivo identificar as consequências proporcionadas pelo assédio moral em discentes e docentes vinculados aos Programas de Pós-Graduação stricto sensu em uma Universidade Estadual Brasileira. A pesquisa foi caracterizada como abordagem mista, descritiva e estudo de caso. Os dados foram coletados por questionário on-line (126 respostas) e entrevistas (7), sendo estes tratados pela técnica de análise de conteúdo. Constatou-se que as consequências 
envolveram a saúde psíquica (raiva, ansiedade, baixa autoestima, depressão); saúde física (alopecia, aumento de peso, tremedeira); relacional/afetivo (afastamento/perda de amigos, crises conjugais); e trabalho/estudo (desilusão com o meio acadêmico, aumento da carga de trabalho, vontade de desistir da pós-graduação). A partir do que foi constatado nesta pesquisa, acredita-se que o tema merece atenção devido ao seu caráter destruidor, e, além disso, sugere-se, ainda, a construção de medidas efetivas de prevenção e de combate ao assédio moral.

Palavras-chave: Assédio moral; Consequências; Pós-Graduação; Universidade

\section{Workplace bullying in postgraduate courses: The consequences experienced by teachers and students of a Brazilian state university}

Abstract: Postgraduate courses provide a fertile ground for the occurrence of workplace bullying, since both teachers and students are usually overwhelmed by stressful demands and pressure, constant seek for productivism, high competitiveness, and vanity. Therefore, the consequences of this demanding environment can be even more severe, affecting health, work, studies and the private life of the professional. Thus, this article aims to identify the consequences of workplace bullying in students and teachers from stricto sensu postgraduate courses in a Brazilian state university. This research was a descriptive case study, and used a mixed approach. Data was collected through an online question naire (126 answers) and followup interviews (7), which were analyzed through content analysis technique. As a result, it was possible to perceive that there were consequences to mental health (anger, anxiety, low selfesteem, depression), physical health (loss of hair, weight gain, trembling), relational/affective (withdrawal/loss of friends, marital conflict), and work/study (disappointment with academia, increased workload, willingness to drop out of the postgraduate course). The findings indicate that the topic should be further investigated due to its destructive nature. Furthermore, the study suggests the elaboration of effective actions to prevent and combat workplace bullying.

Keywords: Workplace bullying; Consequences; Postgraduate courses; University

\section{Acoso moral en el postgrado: Las consecuencias experimentadas por docentes y discentes de una Universidad Estatal Brasileña}

Resumen: El Postgrado presenta un contexto fértil para la ocurrencia de acoso moral, pues tiene en sus prácticas intensas demandas y presiones, búsqueda frecuente de productividad, alta competitividad y vanidad. Por lo tanto, las consecuencias de este ambiente exigente pueden ser aún más graves y afectar la salud, el trabajo, los estudios y la vida privada del profesional. A la vista de lo que se encontró, este artículo tiene como objetivo identificar las consecuencias proporcionadas por el acoso moral en discentes y docentes vinculados a los Programas de Postgrado stricto sensu en una Universidad Estatal Brasileña. La investigación se caracterizó mediante un enfoque mixto, descriptivo y estudio de caso. Los datos fueron recolectados a través de cuestionario online (126 respuestas) y entrevistas (7), siendo estos, tratados por la técnica de análisis de contenido. Se encontró que las consecuencias involucran la salud psíquica (rabia, ansiedad, baja autoestima, depresión); salud física (caída del cabello, aumento de peso, temblor); relacional/afectivo (retraimiento/pérdida de amigos, crisis matrimoniales); y trabajo/estudio (desilusión con el medio académico, mayor carga de trabajo, voluntad de abandonar la escuela de postgrado). Por lo que se encontró en esta investigación, se cree que el tema merece atención debido a su carácter destructivo y, además, se sugiere la creación de medidas efectivas para prevenir y combatir el acoso moral.

Palabras-clave: Acoso moral; Consecuencias; Postgrado; Universidad 


\section{Introdução}

A relação do indivíduo com o seu trabalho e com a sua organização pode fazer eclodir sentimentos e emoções que devem ser gerenciados para que não comprometam o equilíbrio psíquico do trabalhador (Dejours, 2015). Aspectos importantes da história e das condições de vida passam a fazer parte do contexto laboral, por exemplo, as relações estabelecidas em ambiente de trabalho.

O trabalho nunca é neutro em relação à vida dos indivíduos, pois pode gerar sentimentos de prazer ou de desprazer, favorecendo a saúde ou a doença. Para Rates e Leda (2018, p. 39), “o trabalho adquire sentido, redimensionando o dia a dia, permitindo autorrealização nas esferas simbólica, social e afetiva ao trabalhador". O sofrimento é inerente à atividade laboral (Lancman \& Sznelman, 2011). A forma e as condições em que o trabalho é realizado podem acarretar sofrimento e provocar doenças no trabalhador (Merlo, Bottega, \& Perez, 2014). Opera-se, então, uma articulação entre a personalidade do sujeito-trabalhador nas atividades, nas relações e no contexto laboral em que o sujeito está inserido. Essa articulação se expressa entre a sua subjetividade e o real do trabalho, que pode estar em desacordo com os desejos, as aspirações e a singularidade desse sujeito, levando-o ao sofrimento psíquico. O descompasso entre expectativas e realidade que está sendo experienciada e representada pelo indivíduo provoca sentimentos de sofrimento. Concomitantemente, podem surgir experiências exitosas que tragam sentimento de prazer e de satisfação. $\mathrm{O}$ balanceamento dinâmico dessas emoções depende da manutenção da saúde psíquica do sujeito-trabalhador, o que aponta para a relevância desse mecanismo psíquico (Maissiat, Lautert, Pai, \& Tavares, 2015).

Entre as temáticas de prazer e de sofrimento no trabalho, o assédio moral tem causado impacto, gerando aumento das produções científicas e de pesquisas, além de gerar repercussão na mídia nos últimos anos. O contexto de precarização e de intensificação do trabalho, a alta competitividade e a recusa de diferenças são elementos que podem influenciar na ocorrência do assédio moral. A temática compreende condutas abusivas, frequentes e duradouras, que têm por objetivo humilhar, constranger e denegrir um ou mais indivíduos, podendo afetar sua saúde, as condições e o desempenho do trabalho e a vida privada (Hirigoyen, 2006).

O ambiente da Pós-Graduação tem se tornado alvo de pesquisas em relação à temática, pois apresenta situações que podem caracterizar o assédio exatamente como ocorrem em outras organizações. Nunes (2018) relata que 72,2\% dos docentes e discentes vinculados à pós-graduação de uma Universidade Estadual afirmam que a cultura presente na pós-graduação pode contribuir para a ocorrência do assédio. Essa cultura possui algumas características que podem ser identificadas, como: certeza da impunidade; questões grupais (grupos dominantes); cobranças e pressões; exigência de produtividade; competitividade e vaidade. Observa-se que traços dessa cultura estão presentes em muitas organizações, públicas ou privadas, de ensino ou de outros setores.

É importante ressaltar que a pós-graduação já traz pressões e cobranças de trabalho bastante pertinentes, logo, as consequências para aqueles que estão inseridos neste ambiente se agravam exponencialmente. Assim sendo, percebe-se que o docente e o discente de pós-graduação estão expostos ao adoecimento no contexto laboral. Para o docente de pós-graduação, a relação do trabalho e da saúde é permeada por fatores que podem repercutir na identidade e na condição docente, já que a intensificação do seu trabalho e a precarização nas relações de emprego são consideráveis (Trindade \& Bonito, 2011). As exigências por geração de conhecimentos, formação profissional de qualidade e produção de novas tecnologias (Coutinho, 2011; Fernandes, 1996; Mancebo \& Rocha, 2002), produção de artigos científicos, elaboração de relatórios e pareceres técnicos, tarefas administrativas e atividades de gestão são cada vez maiores e se consolidam como tarefas adicionais aos profissionais docentes. A atividade de docência e de pesquisa se refere a um 
processo intelectual, investigativo e criativo, que não se encaixa na lógica produtivista (Garcia, Oliveira, \& Barros, 2008). Com isso, a saúde física e psíquica do docente pode ficar prejudicada em detrimento da produtividade acadêmica, que, cada vez, exige mais horas de dedicação para que se obtenha os resultados esperados.

As condições de trabalho e as pressões vivenciadas pelos docentes na pós-graduação podem interferir diretamente na formação de futuros profissionais ou pesquisadores, atores relevantes para a academia e para a sociedade. Pesquisas demonstram que a ausência de condições organizacionais adequadas, a precarização do trabalho (Coutinho, 2011; Fernandes, 1996), a cobrança por publicações de excelência, a exigência discente intraclasse e extraclasse podem dilapidar a saúde do docente, levando-o ao adoecimento devido à forte pressão e comprometendo a docência e a pesquisa.

Diante dessa contextualização, esta pesquisa tem por objetivo identificar as consequências trazidas pelo assédio moral em discentes e docentes vinculados aos Programas de Pós-Graduação stricto sensu em uma Universidade Estadual Brasileira. A relevância desta pesquisa está reforçada pelas iniciativas de estudo a respeito de assédio moral na pós-graduação, com foco no caráter destruidor do tema e suas consequências para o indivíduo com relação à sua identidade e dignidade. É importante observar que não existe um debate aprofundado sobre os temas como violência, assédio, gênero, discriminação e outros de igual gravidade nas práticas e culturas nefastas da pósgraduação. Logo, ao trazer esse tema à tona pretende-se mostrar a importância de que pró-reitores, coordenadores, docentes, discentes, colegiados, associações de pós-graduação e demais atores o conheçam para que comecem a tratar o assédio moral no trabalho com atenção, dessa forma, quando essas práticas surgirem, não serão naturalizadas ou banalizadas.

\section{Fundamentação Teórica}

O assédio moral no trabalho é considerado temática complexa e dinâmica (Einarsen, Hoel, Zapf, \& Cooper, 2011), que se apresenta como um fenômeno debatido de forma volumosa nas mais diversas áreas da academia, da sociedade e das mídias (Nielsen \& Einarsen, 2018; Nunes, 2016). Embora a discussão seja intensa, seu entendimento (conceito, características, consequências) ainda carece de maiores explanações (Nunes, Tolfo, \& Espinosa, 2018). Para os autores, parte da população e também parte dos pesquisadores têm a compreensão errada do fenômeno, o que acaba prejudicando a sua identificação e banalizando sua ocorrência. Dessa forma, a médio e longo prazo, práticas que poderiam ser consideradas assédio moral são naturalizadas.

No Brasil, existem diversos pesquisadores, militantes e autores que têm trabalhado com a temática do Norte ao Sul do país. Foram considerados os trabalhos de Roberto Heloani e Margarida Barreto como os mais representativos, tanto no aspecto conceitual quanto na questão prática em relação à violência. Dessa forma, apresenta-se como conceito de assédio moral, segundo Heloani e Barreto (2018, p. 53), o seguinte:

Assédio moral é uma conduta abusiva, intencional, frequente e repetida, que ocorre no meio ambiente laboral, cuja causalidade se relaciona com as formas de organizar o trabalho e a cultura organizacional, que visa humilhar e desqualificar um indivíduo ou um grupo, degradando as suas condições de trabalho, atingindo a sua dignidade e colocando em risco a sua integridade pessoal e profissional.

A definição dos autores apresenta aspectos importantes para a compreensão da violência, entre os aspectos apresentados, é possível destacar: o elemento distintivo para definir o que é e o que não é assédio moral, a frequência e a repetição. Ou seja, o assédio moral não é um ato isolado, mas sim as práticas hostis frequentes e duradouras - estando mais relacionadas com o tempo de meses e anos 
do que com dias e semanas (Einarsen et al., 2011; Heloani \& Barreto, 2018; Hirigoyen, 2006; Nunes et al., 2018). Embora determinados atos isolados podem ser considerados violentos, trazendo danos ao alvo, nem sempre eles podem ser considerados assédio, portanto, esse é um ponto de consenso entre os autores que pesquisam a temática.

Para Heloani e Barreto (2015), a "matriz” dos atos hostis está sustentada no autoritarismo (abuso de poder), nas ameaças, nas mentiras, na manipulação do medo, na cooptação e nas várias formas de corrupção. Acrescenta-se a essa lista a recusa em aceitar as diferenças, que podem ser aspectos de gênero, idade, origem, sexualidade, posicionamento político/ideológico e demais aspectos (Hirigoyen, 2006). Tais ações e comportamentos podem ser perpetrados tanto por superiores hierárquicos como por colegas e subordinados.

Entre as situações de assédio moral, Heloani e Barreto (2015) apresentam categorizações atuais que norteiam a realidade latino-americana, como estas ações: a) de assédio para reduzir as possibilidades de a vítima se comunicar adequadamente com outros, inclusive com o próprio autor da violência; b) de assédio para evitar que a vítima tenha a possibilidade de manter contatos sociais; c) de assédio com o intuito de desprestigiar ou de impedir o trabalhador de manter sua reputação pessoal ou profissional; d) de assédio moral mediante o descrédito profissional; e) de assédio moral que afetam a saúde física/psíquica da vítima.

Vivenciar essas situações pode gerar consequências terríveis, principalmente para aquele que é alvo, na sua saúde física e psíquica, no trabalho e na vida privada, além de causar problemas para a própria organização, conforme mostrado na Tabela 1 a seguir.

Tabela 1

Assédio moral: Consequências e efeitos

Saúde Física $\quad$ Saúde Psíquica $\quad$ Trabalho / Organização

\begin{tabular}{|c|c|c|}
\hline Aumento da pressão arterial & Alteração no sono & Absenteísmo \\
\hline $\begin{array}{l}\text { Consumo excessivo de álcool, } \\
\text { tabaco e outras drogas }\end{array}$ & Dificuldade de se concentrar & Afastamento do trabalho \\
\hline Diminuição de energia & Ideação suicida & Aposentadoria prematura \\
\hline Distúrbios digestivos & Insegurança & $\begin{array}{c}\text { Descontentamento com o } \\
\text { trabalho }\end{array}$ \\
\hline Dores de cabeça & Irritabilidade & Erros e acidentes \\
\hline $\begin{array}{l}\text { Dores generalizadas e } \\
\text { esporádicas }\end{array}$ & Manifestações depressivas & Mudança de setor \\
\hline Enjoos & Medo & Perda de habilidade \\
\hline Falta de apetite & Motivação comprometida & Queda na qualidade do trabalho \\
\hline Falta de ar & Paranoia & Redução da produtividade \\
\hline Palpitações & Raiva & Redução de desempenho \\
\hline \multirow[t]{5}{*}{ Tensões musculares } & Sensação de inutilidade & Sem vontade de ir trabalhar \\
\hline & $\begin{array}{l}\text { Transtornos de estresse pós- } \\
\text { traumático }\end{array}$ & $\begin{array}{c}\text { Vontade/ação de pedir } \\
\text { demissão }\end{array}$ \\
\hline & Vontade de chorar por tudo & \\
\hline & Vontade de ficar só & \\
\hline & Vontade de vingar-se & \\
\hline
\end{tabular}

Nota: Adaptado de Hoel, Sparks e Cooper (2001, tradução nossa), Keashly e Jagatic (2003, tradução nossa) e Barreto (2006). 
O assédio moral é considerado violência sutil, ou seja, quem passa por isso, muitas vezes, não percebe de imediato, da mesma forma ocorre com as consequências proporcionadas pela violência, pois o indivíduo só percebe os efeitos dessa violência quando eles já estão intensos e muitas vezes, já é tarde para amenizá-los (Einarsen et al., 2011; Nunes \& Tolfo, 2012). Todavia, embora a violência possa ser sutil, invisível, as consequências podem ser devastadoras e repercutir para a vida inteira do alvo e daqueles que os cercam (Pellegrini, 2016).

No que tange ao ambiente desta pesquisa, a Pós-Graduação stricto sensu, os fatores elencados de sofrimento laboral podem afetar diretamente o bem-estar, a saúde e a qualidade de vida dos docentes e discentes, quando não são ressignificados por eles. Elementos estressantes gerados continuamente causam sofrimento e acabam por minar a resistência do indivíduo, expondo-o ao desgaste. Esse estado pode gerar angústia, insatisfação e tensão e aumentar o absenteísmo (Lima \& Lima-Filho, 2009; Marquese \& Moreno, 2009), principalmente para aqueles desencadeados por distúrbios psíquicos (Gasparini, Barreto, \& Assunção, 2005).

Nos cursos stricto sensu há indivíduos desempenhando diversas atividades que incluem pesquisa, docência, tarefas administrativas, organização de eventos científicos, escrita de relatórios, artigos acadêmicos entre outras atividades que lhes são (im)postas. As pesquisas sobre o significado do trabalho contextualizam o pós-graduando como trabalhador, inclusive no que diz respeito ao recebimento monetário, que é proporcionado pelas agências de fomento e pesquisa por meio das bolsas de pesquisa que possibilitam a dedicação exclusiva dos discentes às atividades da pósgraduação (De Souza, Cavalcanti, \& Cavalcante, 2018).

O estudante da pós-graduação trabalha como um funcionário para os docentes que estão expostos a todos os elementos estressores já elencados neste estudo, apesar de não ser reconhecido formalmente como tal. Por sua vez, o discente está exposto aos mesmos elementos estressores em uma relação dúbia, que já é, por si só, um fator estressor que pode desafiar a sua saúde mental. Todos esses elementos estressores identificados na vida acadêmica do estudante da pós-graduação têm potencial gerador de estresse com consequências negativas à saúde mental, comprometendo a qualidade de vida desse sujeito.

De Souza et al. (2018) realizaram um estudo sobre a Síndrome de Burnout em discentes da pós-graduação de uma Universidade Pública Brasileira, eles constataram que a dimensão da exaustão emocional foi a mais acometida no contexto pesquisado. Todos eles demonstraram sentimentos negativos em detrimento dos positivos, principalmente relacionados ao cansaço e ao estresse, o que sugere o alto nível da presença dessa dimensão, já que a sobrecarga de trabalho é uma das variáveis mais apontadas como predisponentes ao Burnout (Codo, 2006; Lautert, 1995; Meneghini, Paz, \& Lautert, 2011).

Cesar, Sousa, Ribeiro e Oliveira (2018) apontam que os elementos estressores elencados pelos discentes podem ser segmentados nas seguintes categorias: a) características individuais: dificuldades financeiras, insegurança quanto ao futuro, ser mulher, poucas horas de sono, emoções negativas e ansiedade; b) atividades acadêmicas: o uso intenso de habilidades cognitivas culminam em significante estresse para obter desempenho suficiente em atividades de avaliação, cumprimento dos prazos de finalização de atividades, elaboração da dissertação e pressão para executar as atividades acadêmicas; c) relacionamentos interpessoais: conflitos no contexto acadêmico com outros estudantes e orientadores, falta de tempo para dedicar-se a familiares e amigos culminando em conflitos pessoais.

\section{Método}

A pesquisa caracteriza-se como mista incorporada, que, segundo Creswell e Clark (2013), compreende a coleta e análise de dados qualitativos ou quantitativos dentro de um projeto 
quantitativo ou qualitativo. Portanto, a perspectiva quantitativa apresenta dados gerais sobre as consequências identificadas pelos participantes, complementadas pela abordagem qualitativa para compreender significados, sentimentos, comportamentos dos participantes em uma perspectiva mais profunda e subjetiva (Minayo, 1994). Por sua vez, classifica-se também como descritiva e estudo de caso, pois descreve as consequências proporcionadas pelas vivências de situações de assédio moral apresentadas pelos participantes da pesquisa, descobrindo-se, assim, os efeitos que essa violência pode proporcionar.

O lócus desta pesquisa foi uma Universidade Estadual brasileira, que, até 2017, apresentava aproximadamente 600 servidores docentes (dados oficiais da instituição não apresentaram o quantitativo de docentes vinculados aos Programas de Pós-Graduação) e 2.312 discentes (mestrado e doutorado). Não foi definida uma amostra para a pesquisa, uma vez que os pesquisadores entraram em contato com todos os Programas de Pós-Graduação (PPG) para divulgação da pesquisa, além do envio de e-mails para discentes e docentes que divulgaram seus contatos nas páginas dos PPGs.

Foram enviados 50 e-mails para as secretarias dos PPGs e 1.112 e-mails para os discentes e docentes. Por fim, foram computadas 126 respostas do questionário por completo, no entanto, o tema foco deste artigo (consequências do assédio moral) foi apresentado por apenas 44 respondentes que se identificaram como vítimas de assédio moral.

A coleta dos dados ocorreu por meio de duas formas: questionário on-line (abertas e fechadas) para se ter uma visão mais abrangente do fenômeno pesquisado e entrevistas individuais com roteiro semiestruturado para complementar e exemplificar com mais detalhes as experiências dos participantes. Portanto, a estrutura de ambos os instrumentos foi composta de: termo de consentimento livre e esclarecido; dados sociodemográficos; assédio moral no trabalho - tendo como base as pesquisas de Nunes (2016).

As entrevistas aconteceram paralelamente à aplicação do questionário mediante a disponibilização do participante dentro do próprio instrumento on-line, no qual o pesquisado poderia deixar seus dados (e-mail e/ou telefone) para posterior contato. Dessa forma, ocorreram análises das respostas dos participantes com o intuito de observar se poderiam apresentar mais informações sobre o fenômeno estudado. Dos 20 participantes que se disponibilizaram, 15 foram selecionados e apenas sete retornaram o contato e foram entrevistados. Nas entrevistas, os aspectos pertinentes ao fenômeno de estudo foram aprofundados.

Em relação à técnica de análise de dados, utilizou-se a análise de conteúdo desenvolvida por Bardin (2016), que se caracteriza pela: pré-análise (organização do material, transcrição e demais); exploração do material (desenvolvimento de categorias); e pelo tratamento dos resultados, inferência e interpretação (análise reflexiva e crítica dos resultados). Dessa forma, a partir da literatura do tema (Freitas, Heloani, \& Barreto, 2008; Hirigoyen, 2006; Nunes, 2016; Nunes \& Tolfo, 2012), os dados foram categorizados em consequências na: saúde (física e/ou psíquica); relacional/afetivo; trabalho/estudo.

Ademais, a pesquisa foi enviada e aprovada pelo Comitê Permanente de Ética em Pesquisa com Seres Humanos da instituição pesquisada. Logo, o respeito às normativas sobre o manejo correto dos conteúdos de dimensões da vida humana foi praticado conforme prevê a Resolução $n$. 466, de 12 de dezembro de 2012, do Conselho Nacional de Saúde (Brasil, 2012).

Por fim, para garantir a proteção e o anonimato dos participantes, os respondentes do questionário on-line foram identificados com a letra "Q" seguida pelos respectivos número (1 a 36: docente; 37 a 126: discentes de mestrado ou doutorado) e os entrevistados com a letra " $E$ " (1 e 4 : docentes; 2, 3, 5 a 7: discentes de mestrado ou doutorado). 


\section{Análise e Interpretação dos Dados}

Inicialmente, é fundamental descrever o público pesquisado: discentes e docentes vinculados aos PPGs da universidade analisada. Conforme apresentado anteriormente, dos 126 respondentes do questionário on-line, cerca de 44 participantes se identificaram como vítimas de assédio moral. Portanto, esta seção apresentará as informações sobre esse público.

Tabela 2

Descrição dos participantes (questionário on-line e entrevistas)

Dados do Questionário (44) $\quad$ Freq. $\quad \%$

Sexo: Feminino

$29 \quad 65,9$

Idade: 25 a 35 anos

$26 \quad 59,1$

Estado Civil: Casado(a)/União Estável

$22 \quad 50$

Vínculo com a Pós-Graduação: Docente

1125

Vínculo com a Pós-Graduação: Discente de Mestrado $14 \quad 31,8$

Vínculo com a Pós-Graduação: Discente de Doutorado $\quad 19 \quad 43,2$

Centro de Vínculo: Ciências Sociais Aplicadas $\quad 14 \quad 31,8$

Tempo de trabalho na Universidade (Docentes): mais de 25 anos $\quad 4 \quad 36,4$

Tempo de trabalho na Pós-Graduação (Docentes): de 1 a 5 anos $\quad 6 \quad 54,5$

Cargo de Direção na Pós-Graduação (Docentes): Não $\quad 770$

Tempo que cursa Pós-Graduação (Discentes): de 2,5 anos a 3 anos $\quad 8 \quad 24,2$

Bolsista (Discente): Sim $\quad 21 \quad 63,6$

Obrigado a cumprir carga horária semanal (Discente): Não

\begin{tabular}{lc}
19 & 57,6 \\
\hline req. & $\%$
\end{tabular}

\begin{tabular}{ll}
\hline Sexo: Feminino & 5 \\
Vínculo com a Pós-Graduação: Discente de Doutorado & 3 \\
Vínculo com a Pós-Graduação: Discente de Mestrado & 2 \\
Vínculo com a Pós-Graduação: Docente & 2 \\
Tempo na Pós-Graduação: de 1,5 a 2 anos & 2 \\
Bolsista: Sim & 3 \\
\hline
\end{tabular}

Nota: Dados primários.

A caracterização dos participantes possibilita a compreensão do público respondente, foco desta pesquisa, e das consequências proporcionadas pelo assédio moral. Portanto, a partir dessa breve descrição, serão apresentadas as análises e as interpretações dos dados obtidos no questionário on-line e nas entrevistas.

\section{A Contextualização do Assédio Moral}

Esta subseção contextualiza algumas situações de assédio moral identificadas na pesquisa por meio das respostas dos docentes e discentes no questionário on-line e também nas entrevistadas realizadas. Julga-se importante discorrer sobre esses elementos para compreender o aspecto interpessoal, organizacional e cultural presente na pós-graduação que pode favorecer o assédio moral. Dessa forma, é possível relacionar o assédio moral vivenciado pelos participantes e as consequências que interferiram na saúde de cada um (física e/ou psíquica), na vida pessoal e laboral e nas relações de trabalho. 
Na pesquisa, foram identificadas situações de assédio moral, em maior número, relacionadas ao trabalho, que consistem em: perseguições relacionadas às atividades e ao desempenho do alvo e ações/comportamentos que dificultam as condições de trabalho; assédio pessoal, que implica hostilidades, humilhações e constrangimentos dirigidos a situações ou características particulares do alvo, além de isolamento e exclusão dos grupos sociais; e assédio por intimidações físicas ou sexual, que compreendem agressões verbal, física e/ou sexual.

Situações relacionados ao trabalho, como ter opiniões e pontos de vista ignorados, são comuns em qualquer organização. No âmbito da pós-graduação, os relatos apresentados pelos participantes se referem principalmente ao posicionamento político e ideológico, ou seja, dependendo da linha ideológica que o indivíduo segue, algumas hostilidades podem aparecer. No relato de discentes, esse elemento influenciou diversas práticas hostis, uma delas vindo do professor da disciplina que inseria sua ideologia como algo incontestável dentro de sala de aula. "A gente começou a falar o que ele queria ouvir e ler, já que ele não aceitava ou ironizava frequentemente a nossa opinião. Era uma questão de ideologia, política. Ele nunca deixou claro o posicionamento dele, mas dava para ver" (E7).

Percebe-se nesse relato uma gestão assediosa por parte do docente contra os discentes que, conforme afirma Nunes (2016), pode levar até outros colegas a agirem com desprezo com aqueles que pensam diferente como uma forma de fazer parte do grupo do agressor ou por medo de serem as próximas vítimas. Ignorar o outro, ainda mais em um ambiente plural e de debate, é promover sentimento de insegurança e de medo, exposição negativa do outro, e levar a crer perante o grupo que aquele que é contra a ideologia "dominante" (do docente no caso) está fadado a sofrer punições (Hirigoyen, 2006; Nunes, 2016).

A relação entre o docente e seus pares, muitas vezes, ocorre de forma cordial quando favorece a ambos. Estar como docente na Pós-Graduação é um status que coloca automaticamente aqueles dentro desse sistema em destaque. A vaidade nesse meio é alta e envolve indivíduos que se consideram melhores do que os outros e desejam ser destaque, ter seus egos inflados, podendo também menosprezar os outros e seus trabalhos como forma de se engrandecer (Nunes, 2016). Segundo um dos participantes, "A vaidade é cotidiana na pós-graduação. Se manifesta quando um docente passa o tempo todo criticando os colegas, quando ele acredita que os seus artigos têm mais qualidade do que os trabalhos dos demais e passa a desqualificar os outros" (Q1). Nesse interim, para Silva, Heloani e Piolli (2012, p. 381), "o individualismo é incitado pela regulação avaliativa punitiva, e, às vezes, sutil, manipulatória da vaidade e instauradora de competitividade mórbida".

Um dos males da nossa sociedade, o preconceito, também é identificado dentro da pósgraduação, por exemplo, a origem e a religião, conforme relatos: "Maioria dos alunos do Programa são de fora, Nordeste e Norte. E eles acabam se sentindo constrangidos com 'brincadeiras' feitas por outros alunos frequentemente" (E6); "Ele ficava fazendo muito julgamento pessoal, falava 'você fala muito como crente' e criticava isso, porque eu não devia usar esse linguajar... Sempre achava uma maneira de me hostilizar. E eu com medo, eu ia nas reuniões com medo" (E5). A recusa da diferença de uma característica da vítima pode ser um dos gatilhos para comportamentos e práticas de assédio moral (Hirigoyen, 2006; Tolfo, Silva, \& Krawulski, 2015).

Outro elemento recorrente é a exposição do(s) discente(s) sobre seus posicionamentos dentro de sala de aula, não no sentido de ideologia ou político já mencionado, mas a humilhação e a diminuição do indivíduo perante o coletivo. Segundo a participante, "Dei minha opinião em uma atividade na aula ... e o professor agiu de uma forma muito irônica. Para mim, foi muito constrangedor. Hoje eu vejo que foi um aprendizado... E isso se repetiu por outras aulas, ele fica fazendo piadas e a turma toda ri... eu me sinto humilhada" (E7).

Diversas situações de assédio moral tiveram ocorrência (frequente e duradoura) acima de $30 \%$ dos participantes, entre elas: a) foi obrigado a realizar um trabalho acima/abaixo do seu nível 
de competência; alguém reteve informações que podem afetar o seu desempenho; b) foi atribuído mais trabalho a você do que a outro colega; c) foi solicitado a realizar tarefas despropositadas ou com um prazo impossível de ser cumprido; d) foi ignorado, excluído ou "colocado na geladeira"; e) foi humilhado ou ridicularizado em relação ao seu trabalho; e) espalharam boatos ou rumores sobre você. Por sua vez, duas situações ficaram acima dos $40 \%$ de frequência, a saber: a) suas opiniões e pontos de vista foram ignorados; e b) foi exposto a uma carga de trabalho excessiva.

Os relatos anteriores são situações recorrentes na pós-graduação em qualquer instituição brasileira e até internacional. Pode-se compreender, portanto, que tais práticas e comportamentos fazem parte do modus operandi desse meio, os quais são perpetrados, incorporados e naturalizados pelos docentes e discentes (Nunes \& Mello Neto, 2018). Ou seja, é algo inserido na própria cultura da pós-graduação.

A dinâmica organizacional acadêmica reproduz a estrutura da sociedade brasileira que é autoritária, oligárquica, hierárquica e vertical, tecida por desigualdades profundas (Chauí, 2016), o que resulta em exclusões sociais, políticas e culturais. $\mathrm{Na}$ academia, há reprodução de posicionamentos políticos e ideológicos da sociedade em cada área de conhecimento, que visa a manter e a fortalecer o mainstream. A passagem para pertencer a tão seleto grupo social é alcançada com a capacidade de o docente/discente reproduzir o discurso vigente e, tal intento, pode ser alcançado com a restrição e a punição ao pensamento crítico. Nesse contexto organizacional, o assédio moral é a estratégia utilizada para restringir a liberdade do livre pensar e a elaboração de pesquisas que visem à evolução teórica que possa explicar os fatos sociais estudados sob novas perspectivas.

Nesse sentido, observou-se também que $90,9 \%$ dos alvos de assédio moral não realizaram a denúncia, formal ou informal (apenas verbais), no ambiente universitário ou externo (justiça). Os principais motivos são os mesmos daqueles em pesquisas similares: porque não adianta denunciar; medo em sofrer algum prejuízo se denunciasse; criar um clima desagradável no ambiente laboral; e exposição da vítima perante o grupo e organização. Segundo um dos participantes, "Há a sensação de que pouco será feito. Medo de a pessoa que receber a denúncia usá-la contra mim ou criar uma situação prejudicial a mim. Não há um setor ou grupo que de fato faça frente, proteja ou ampare em situações assim" (P115).

O consenso entre os participantes da pesquisa é o de que existe um protecionismo presente dependendo quem for o agressor, além da falta de amparo institucional. Quando o agressor é um docente e hostiliza um discente, o desequilíbrio de poder nessa relação é alto, e a proteção em geral recai no docente. Por sua vez, quando o assédio é entre docentes, a punição ou a proteção depende de qual grupo os envolvidos fazem parte.

A sociedade brasileira é marcada por diversos traços culturais críticos, entre eles estão o corporativismo, a lealdade às pessoas, o paternalismo e a impunidade, que garantem o funcionamento desse sistema (Alcadipani \& Crubellate, 2003). Nesse sentido, as Universidades também incorporam, naturalizam e expandem esses traços culturais, os quais são elementos que podem favorecer a ocorrência do assédio moral e outras manifestações de violência e práticas de comportamentos antiéticos (Nunes, 2016).

Em um ambiente que já apresenta constantes pressões internas e externas, cobranças exacerbadas, questionamentos de capacidade e busca incessante pela produtividade, os quais geram efeitos diversos para os indivíduos que nele interagem, a ocorrência do assédio moral potencializa os efeitos negativos. Assim, nesse ambiente "insalubre" somado às violências sofridas, a vivência durante o curso de mestrado ou doutorado para os discentes, por exemplo, é intensa e paulatina uma vez que o tempo destes é limitado, porém, eles podem carregar as consequências provocadas ao longo de suas vidas. Por outro lado, os docentes da mesma forma carregam e seguram as 
consequências negativas por desejarem permanecer vinculados à pós-graduação, o que pode provocar a intensificação dos efeitos ao longo do tempo.

\section{Consequências do Assédio Moral}

As informações a seguir apresentam as consequências e os efeitos proporcionados pelas situações de assédio moral vivenciadas e/ou vividas pelos discentes e docentes, as quais podem afetar a saúde psíquica e física, relacional e afetiva, além do trabalho ou estudo no ambiente da pósgraduação. Dessa forma, a Tabela 3 apresenta resumidamente a incidência dessas categorias na pesquisa.

\section{Tabela 3}

Consequências do assédio moral

\section{Consequências do Assédio Moral Freq. \%}

\begin{tabular}{lcc}
\hline Saúde Psíquica & 44 & 54,3 \\
Saúde Física & 3 & 3,7 \\
Relacional/Afetivo & 12 & 14,8 \\
Trabalho/Estudo & 22 & 27,2 \\
Total & $\mathbf{8 1}$ & $\mathbf{1 0 0}$ \\
\hline
\end{tabular}

Nota: Dados primários.

A Tabela 3 apresenta o que a própria literatura relata sobre os casos de assédio moral, aqui estão elencadas as consequências causadas pelo assédio que afetam principalmente a saúde psíquica das vítimas (Freitas et al., 2008; Hirigoyen, 2006). Ademais, essas consequências afetam em maior ou menor grau outras esferas da vida do indivíduo. Logo, nas próximas subseções serão apresentados os principais efeitos de cada categoria e as verbalizações dos pesquisados para contextualizar a gravidade de consequências que o assédio pode proporcionar para o alvo.

\section{Consequências do Assédio Moral: Saúde Psíquica e/ou Física}

Segundo os participantes, a maioria dos efeitos proporcionados pela vivência de situações de assédio ocorre na sua saúde psíquica (55,7\%), e, com isso, podem surgir efeitos para outros âmbitos: no físico, no desempenho do trabalho e no relacionamento com colegas e familiares (Barreto, 2000).

É importante enfatizar que as consequências do assédio podem ser devastadoras e severas para o alvo, ou seja, o assédio moral não é uma "frescura" do indivíduo (Freitas et al., 2008; Nunes \& Tolfo, 2012; Pellegrini, 2016). Para esses autores, ao longo do tempo, as consequências podem se intensificar devido ao constante "massacre" que o alvo vivência, além disso, esse "massacre" pode causar danos irreparáveis.

Ao tratar da saúde psíquica e física, Hirigoyen (2006, p. 162) ressalta que "um choque físico pode ter efeitos psiquiátricos, e um choque emocional pode implicar em uma série de consequências. Passa-se, assim, do físico ao psíquico e reciprocamente. A representação ou o temor do acontecimento cria por sua vez a mesma síndrome”. Ou seja, os efeitos na saúde física podem repercutir na saúde psíquica e, assim, mutuamente. A Tabela 4, a seguir, apresenta as consequências identificadas na saúde psíquica e física dos participantes. 
Tabela 4

Consequências do assédio moral: saúde psíquica e física

\begin{tabular}{|c|c|c|c|}
\hline Saúde Psíquica & Freq. & $\%$ & Participantes \\
\hline Raiva & 4 & 9,1 & Q4; Q6; Q113; Q115 \\
\hline Ansiedade & 3 & 6,8 & Q37; Q70; Q113 \\
\hline Baixa autoestima & 3 & 6,8 & Q15; Q43; Q117 \\
\hline Choro & 3 & 6,8 & Q70; Q78; Q113 \\
\hline Depressão & 3 & 6,8 & Q37; Q83; Q113 \\
\hline Desmotivação & 3 & 6,8 & Q6; Q17; Q104 \\
\hline Constrangimento & 2 & 4,5 & Q54; Q104 \\
\hline Danos psicológicos & 2 & 4,5 & Q49; Q113 \\
\hline Desânimo & 2 & 4,5 & Q59; Q115 \\
\hline Frustração & 2 & 4,5 & Q109; Q115 \\
\hline Sentimento de inferioridade & 2 & 4,5 & Q70; Q113 \\
\hline Sentimento de incompetência / incapacidade & 2 & 4,5 & Q37; Q113 \\
\hline Tristeza & 2 & 4,5 & Q78; Q109 \\
\hline Outros & 11 & 25,4 & $\begin{array}{l}\text { Q30; Q37; Q39; Q70; Q84; Q113; } \\
\text { Q120 }\end{array}$ \\
\hline Total & 44 & 100 & \\
\hline Saúde Física & Freq. & $\%$ & Participantes \\
\hline Alopecia (perda de cabelo) & 1 & 33,3 & Q70 \\
\hline Aumento de peso & 1 & 33,3 & Q113 \\
\hline Tremedeira & 1 & 33,3 & Q113 \\
\hline
\end{tabular}

Nota: Os itens em Saúde Psíquica com frequência menor que 2 focam alocados em "Outros", a saber: aborrecimentos; dificuldade de concentração; dificuldade na leitura; inquietação; insônia; mal-estar; ideação suicida; sensibilidade; síndrome do pânico; sofrimento; vulnerabilidade.

As consequências para a saúde dos participantes assediados, tendo como base os respondentes do questionário on-line, não tiveram muito destaque na incidência dos efeitos. O que não significa que não ocorreram ou que não foram graves, pois, muitas vezes, não são identificadas, assim como a violência em si (Hirigoyen, 2006, 2008).

A raiva, elemento com maior frequência, é um sintoma manifestado principalmente pelos homens (Barreto, 2008; Freitas et al., 2008), uma vez que, culturalmente, o homem não deve demonstrar fraqueza e tende a ter pensamentos e sentimento mais agressivos, como raiva e vingança. Por sua vez, segundos os autores, as mulheres tendem a ter mais tristeza e choro, por exemplo. No entanto, tanto os homens quanto as mulheres participantes da pesquisa apresentaram o sentimento de raiva, mas, não contextualizando, por exemplo, se esse sentimento é direcionado ao agressor por ter passado pela situação hostil ou por não ter reagido.

O assédio moral representa um sofrimento que pode gerar ansiedade, vergonha, medo, baixa autoestima e diversos sentimentos que inferiorizam e inibem o indivíduo em reagir, e com o tempo, os efeitos pioram podendo levar ao suicídio (Barreto \& Venco, 2011). Para Hirigoyen (2006), quando o indivíduo não consegue reagir, debilitado psiquicamente para isso, ele acaba ficando alienado e sente-se afastado de si.

Em pesquisa desenvolvida por Levecque, Anseel, Beuckelaer, Heyden e Gislef (2017) com discentes de doutorado, os autores identificaram que grande parte destes experienciaram algum distúrbio psicológico ou o risco de desenvolver algum transtorno psiquiátrico. Para eles, os efeitos 
mais comuns foram: estar sobre pressão constante, demonstrar tristeza, depressão e problemas para dormir devido às preocupações, sentir falta de habilidade para ultrapassar as dificuldades e não conseguir aproveitar as atividades diárias.

Como forma de contextualizar melhor as consequências do assédio moral, tendo como foco principal a saúde (psíquica e/ou física), algumas verbalizações foram selecionadas: "Eu acho que o que mexe no psicológico e na saúde dá uma dor de estômago quando essas coisas acontecem” (E1); "Eu emagreci bastante, porque eu não comia muito. Eu comia correndo e pouco para dar tempo de fazer as coisas. Eu dormia, mas eu só sonhava com os textos, acredito que isso vem muito dessa cobrança” (E7);

Hoje em dia quando eu falo sobre a Pós, eu consigo levar tranquilo, não é uma coisa que dá mais aperto no coração sabe, de dar palpitação e transpirar, isso hoje não mais... Essa questão do bloqueio de escrita também afetou minha autoestima, até onde eu sou capaz de escrever uma coisa realmente boa... Tive estresse a ponto de não conseguir dormir, aí começa a repercutir, comecei a comer mal... Eu sabia que estava bebendo muito, mas eu falava "cara eu não consigo dormir, eu preciso estar alcoolizado e realmente dopado para deitar e capotar na cama..." Eu ia para lá [dar aula] de ressaca, não era uma aula boa... Comecei a ganhar peso, eu entrei num programa de doutorado com $83 \mathrm{~kg}$ e consegui atingir 100kg. Eu via que estava inchado, que estava cansado... Eu via que começava a degradar cada vez mais a saúde... Tinha surtos, as vezes acordava no meio da noite e o coração palpitando acelerado, porque eu sonhei que tinha uma coisa para entregar naquele prazo. Tinha uma inquietação, esse transtorno psíquico que tinha de ansiedade... Minha coluna começou a doer muito... Meu colesterol começou a estourar, porque eu não controlava nada. O fígado, eu estava bebendo, passei quase 2 anos bebendo, bebia quarta, quinta, e na sexta saia com minha esposa, e não ia deixar de me divertir. Estava bebendo demais... O álcool usava realmente para anestesiar mesmo, porque eu sabia que eu não acordaria de novo porque eu estava capotado... Quando eu comecei a fazer o tratamento de psicoterapia, comecei a ver os problemas... Tive dor de estômago leve, mas dormindo já resolvia... Imagina, como meu estômago deveria estar cheio de úlcera, talvez por problemas similares, beber, estresse, comer mal. $\mathrm{Na}$ cabeça, pensamentos de eu não estou mais bem, medo de fracassar, de frustrar. (E2)

Eu fiz uns 2 meses de atendimento psicológico aqui em Maringá, mas aí estava muito caro. Aqui na UEM eles têm um grupo de atendimento psicológico, entrei em contato e não tinha vaga, aí eu falei pra ela "olha, eu estou pensando em me matar" passei por todo o processo de depressão profunda. Pensava em me suicidar várias vezes por semana sabe, é até horrível de se dizer, mas não tinha vaga... E nesse meio tempo, que ficava sozinha, eu pensava "vou me matar, porque eu vou ficar em casa fazendo isso? Eu não sou capaz, não sou competente". Fiquei um tempo assim, vou me matar, vou me jogar na cerca que tem aquelas pontas. Eu ficava um tempão embaixo do chuveiro chorando. E aquele sentimento ruim dentro, uma angústia terrível, de vontade de morrer, de sumir, desaparecer, nada fazia sentido para mim... E eu ameaçava para ele [marido] "não aguento mais... aí eu tomava todo o remédio. (E5)

Como eu comecei a ver que os sintomas da depressão ficaram fortes. Todo mês era um problema de saúde que eu tinha, um mês era bexiga, no outro era estômago, era no outro cabeça, no outro era útero. Tive problema de útero muito forte, de dor. 
Desregulou meu ciclo menstrual, eu fiquei sem menstruar, o que nunca aconteceu na minha vida, e eu não estava grávida. Foi assim, uma dor muito forte que eu tive. Fui na ginecologista para saber, e era do sistema nervoso. Além da exigência do doutorado, que era muito, tinha até semana que eu dormia umas $15 \mathrm{~h}$ na semana. Sinusite atacou bastante também... Toda vez que eu me lembrava já começava a tremer, tinha ansiedade de nervoso. Aí eu só fui começar com remédio em janeiro, isso porque eu tinha amostra grátis do antidepressivo. Comecei a tomar, e engordei $20 \mathrm{~kg}$ quase. Toda vez que eu começo a entrar em colapso, eu começo a tremer. Quando eu lembro do que ele fala eu começo a tremer... Me confundia com as datas, daí que eu tive que tomar remédio para começar a fazer as pesquisas. Começava a chorar porque já estava me sentindo hostilizada. (E5)

As verbalizações anteriores relatadas pelos entrevistados apresentam alguns efeitos que prejudicaram a saúde física e psíquica. Por sua vez, E2 e E5 apresentaram mais detalhes das consequências proporcionadas pelo assédio que vão desde o bloqueio da escrita, situação que acontece de forma frequente na pós-graduação, ao início de vícios diversos e até de suicídio.

Segundo Hirigoyen (2006, p. 161), "após um certo tempo de evolução dos procedimentos de assédio, os distúrbios psicossomáticos passam quase sempre ao primeiro plano. O corpo registra a agressão antes do cérebro, que se recusa a enxergar o que não entendeu”. Para a autora, alguns desses distúrbios se manifestam por emagrecimentos ou aumento rápido de peso $(15 \mathrm{a} 20 \mathrm{~kg} \mathrm{em}$ alguns meses), distúrbios digestivos (gastrites, úlceras de estômago), distúrbios endócrinos (problemas de tiroides, menstruais), crises de hipertensão arterial, vertigens, doenças de pele e outros.

O indivíduo em depressão que sofre assédio moral tem seu quadro piorado quando a violência se prolonga ou se torna mais intensa, podendo apresentar complexo de culpa, desinteresses por seus próprios valores e atividades, apatia, tristeza, não se sente capaz de realizar suas atividades (Hirigoyen, 2006). E nesse estado precisam ainda mais de constante vigilância, pois a possibilidade de suicídio é risco real (Barreto \& Venco, 2011).

\section{Consequências do Assédio Moral: Relacional/Afetivo}

Em decorrência das consequências causadas à saúde da vítima, o mesmo acaba afetando os seus relacionamentos, no trabalho, na sua rede social e familiar, podendo intensificar ainda mais o sofrimento causado durante a violência. Foram identificadas algumas situações relatadas pelos participantes, conforme pode ser visualizado na Tabela 5 a seguir.

Tabela 5

Consequências do assédio moral: relacional/ afetivo

\begin{tabular}{lccl}
\hline \multicolumn{1}{c}{ Relacional/Afetivo } & Freq. & $\mathbf{0}$ & \multicolumn{1}{c}{ Participantes } \\
\hline Afastamento/Perda de amigos & & & \\
Crises conjugais & 2 & 33,3 & Q28; Q34; Q78; Q113 \\
Desgaste nas relações de trabalho & 2 & 16,7 & Q78; Q113 \\
Afastamento da vida social & 2 & 16,7 & Q7; Q49 \\
Afastamento da família & 1 & 8,3 & Q78 Q86 \\
Crises familiares & 1 & 8,3 & Q113 \\
Total & $\mathbf{1 2}$ & $\mathbf{1 0 0}$ & \\
\hline
\end{tabular}

Nota: Dados primários. 
Ao sofrer a violência, o indivíduo-alvo tende a se isolar dos colegas de trabalho, dos amigos e dos familiares por medo, receio de julgamento e vergonha de expor o seu sofrimento (Freitas et al., 2008; Nunes \& Tolfo, 2012; Pellegrini, 2016). Porém, segundo os autores, esse isolamento só piora a situação da vítima, promovendo uma potencialização do seu sofrimento, que repercute na sua relação com os outros, podendo promover sentimentos de desamparo familiar.

As verbalizações em sequência contextualizam alguns desses aspectos: "Houve um distanciamento das pessoas, até da família. Às vezes, estava estressada. Só que, assim, ele [marido] estava fazendo pós-graduação, então, ele entende também” (E3);

Prejudicou o meu relacionamento com meus pais, acabei projetando frustrações neles que não são exatamente deles. E eu vejo que prejudicou, e eu não quero que prejudique mais... Ao mesmo tempo fragilizou a relação que eu tinha com os amigos... Com relação ao meu casamento, a minha esposa é muito querida. Foi uma pessoa que eu sentia amparo, e até falei assim, eu prefiro perder o doutorado que perder meu casamento. E isso já falei nitidamente, porque vem esses comentários, "às vezes, deixa um pouco de lado a esposa, porque tem trabalho". Aí eu falo, a minha esposa é minha vida, o doutorado não. Na vida sexual acaba prejudicando, você acaba acumulando energia para um lado e acaba faltando para outro lado. Minha vida sexual era boa de forma geral, mas teve um momento que ela chegava a prejudicar. Imagina, dois meses sem nada e recém-casados, não é a vida que eu quero. Também não abdiquei de viajar com ela, viagem curta, de 3-4 dias, mas ia com peso na consciência. Então, eu vejo que afetou a vida pessoal (E2).

Esse daqui [marido], eu falo para ele que ele não entende o que é assédio moral, depressão. Ontem mesmo eu falei pra ele, [Fulano], e eu chorando. [Marido falando] "se eu não entendesse o que você estava passando, a gente estaria separado já". Então, repercutiu sim, porque eu falo para ele, "olha, eu queria que ele sentisse na pele o que eu senti, mas ao mesmo tempo eu não queria”, eu não quero que ninguém sinta (E5).

Os três entrevistados relataram que se afastaram dos amigos, familiares e cônjuge. Os cônjuges de E2 e E3 fizeram/fazem pós-graduação, então, segundo eles, os companheiros compreendem como é viver um mestrado ou doutorado. No entanto, não ficou evidenciado nas conversas se esse "saber" também inclui questões hostis ou se tais situações são naturalizadas pelos cônjuges como parte do processo.

Em entrevista realizada com E5, na qual seu marido participou em determinados momentos apoiando-a, foi questionado se o assédio moral teve influência na relação conjugal. Ficou evidenciado pelas falas e pelos comportamentos que todo o processo e seus efeitos afetaram o relacionamento. Além disto, o cônjuge não consegue compreender claramente o processo em que E5 passou e passa e, em vários momentos, ele falou que ela deveria ter confrontado o agressor, como se a situação de assédio só tivesse ocorrido porque ela "permitiu", que não teve uma reação de confrontar.

Determinados comportamentos e atitudes por parte de pessoas que não estão ou não vivenciaram situações de assédio acabam por prejudicar ainda mais o alvo, pois o indivíduo não encontra um amparo afetivo/emocional e no futuro evita relatar novos acontecimentos. Para Hirigoyen (2006; 2008) e Freitas et al. (2008), só quem realmente compreende todo o sofrimento proporcionado pela vivência de situações de assédio moral é quem passou/passa pela violência.

A estrutura familiar/conjugal, segundo Cassitto, Fattorini, Gilioli, Rengo e Gonik (2003), Caldas (2007) e Yung (2011), é afetada, pois há momentos de crises quando um ou mais membros 
vivenciam situações de assédio moral. Pellegrini (2016) complementa isso ao relatar que existem mudanças na rotina e na organização da família diante da vivência de assédio moral, com repercussões para os relacionamentos entre os cônjuges e com seus filhos. Logo, para a autora, o compartilhamento dessas experiências é importante para manter a estrutura familiar/conjugal e também para construir medidas de enfrentamento e de fortalecimento do assediado(s) e familiar.

\section{Consequências do Assédio Moral: Trabalho/Estudo}

Embora o assédio moral provoque principalmente consequências na saúde da vítima, os efeitos também extrapolam esse limiar - conforme explanado nesta pesquisa. O assédio também repercute no desenvolvimento das atividades e na adesão do indivíduo ao seu trabalho e, no caso, na sua permanência na pós-graduação.

Tabela 6

Consequências do assédio moral: trabalho/ estudo

\begin{tabular}{lccl}
\hline \multicolumn{1}{c}{ Trabalho/Estudo } & Freq. & $\mathbf{0}$ & \multicolumn{1}{c}{ Participantes } \\
\hline Desilusão com o meio acadêmico/pós-graduação & 4 & 18,2 & Q15; Q42; Q113; Q123 \\
Aumento da carga de trabalho & 3 & 13,6 & Q9; Q39; Q86 \\
Vontade de desistir da pós-graduação (discente) & 3 & 13,6 & Q49; Q78; Q101 \\
Queda na produtividade & 2 & 9,1 & Q28; Q84 \\
Sem vontade de trabalhar/ir para a aula & 2 & 9,1 & Q15; Q49 \\
Sentimento de impunidade/injustiça & 2 & 9,1 & Q4; Q113 \\
Vontade de desistir da docência & 2 & 9,1 & Q15; Q113 \\
Afastado da função & 1 & 4,5 & Q4 \\
Atraso dos trabalhos & 1 & 4,5 & Q105 \\
Bloqueio da escrita & 1 & 4,5 & Q115 \\
Perda da bolsa & 1 & 4,5 & Q101 \\
Total & $\mathbf{2 2}$ & $\mathbf{1 0 0}$ & \\
\hline
\end{tabular}

Nota: Dados primários.

Observa-se, pelos dados apresentados na Tabela 6 , a desilusão e a vontade de desistir da pósgraduação como situações que ocorrem com frequência, pois o próprio ambiente proporciona lembranças e sensações que não são desejadas pelos alvos, além de possível reencontro com o(s) agressor(es) (Hirigoyen, 2008; Nunes \& Tolfo, 2012).

Teve dia que eu nem fui para a aula de tão estressada que eu estava. Deitei na cama, fiquei por lá. "Eu não vou, não vou". Cheguei a pensar em desistir, e eu acho que não só eu, várias pessoas... Tem bastante gente ali que desistiu, uns $25 \%$, é muito gente. Gente que saiu com depressão, com coisas assim. Um monte de gente tomando ritalina, passando mal de tomar energético (E3).

O efeito relacionado ao trabalho/estudo refletiu mais na identificação com o ambiente acadêmico, e não, especificamente, com a produtividade (leituras e escritas), como é mais comum nas pesquisas. Possivelmente, pelo fato de a pós-graduação ser uma questão opcional (principalmente para os docentes) e momentânea para os discentes (que podem procurar outros Programas), a vivência de situações de assédio faz com que se pense sobre a importância em continuar ou não.

Corroborando essas questões, foi perguntado aos discentes, respondentes do questionário, "se os acontecimentos ocorridos na pós-graduação influenciam na carreira/escolha como docente". As respostas apresentaram dois elementos principais, o repensar sobre a profissão e o de não 
reproduzir as práticas hostis vivenciadas em sala de aula. "Se eu for docente um dia nunca, jamais tratarei um aluno como fui tratada" (Q37); "Não sei se quero fazer parte desse mundo que acha normal a falta de respeito com o outro" (Q78); "Influenciam de forma contundente. São práticas que não pretendo levar para a minha vida profissional” (Q123).

Ademais, a desigualdade de poder, como um elemento presente na cultura e nas práticas da Universidade, que pode favorecer a ocorrência do assédio moral (Nunes, 2016), dentro da pósgraduação, e, principalmente, na relação docente/orientador e discente/orientando, pode ainda provocar sentimentos e efeitos negativos quando essa relação incide o assédio moral: "A gente fica muito vulnerável à pessoa que 'comanda'. Essa pessoa pode mexer os pauzinhos dela. Eles têm muito poder em cima da gente, e se eles quiserem fazer alguma coisa, eles têm como. É a hierarquia, a gente sabe quem manda" (E3).

As verbalizações apresentadas pelos participantes sobre suas vivências de assédio moral vão muito além de consequências "simples e leves", podem ter uma duração longínqua e prejudicar toda sua vida pessoal e laboral (Heloani \& Barreto, 2018). Afeta sua dignidade e projetos futuros, além do sentido e significado em estar cursando uma pós-graduação ou em ser um docente dela (Nunes \& Mello Neto, 2018). O não reconhecimento e a desvalorização do servidor público (docente) e do discente podem afetar o sentido que eles dão ao seu trabalho no presente e nas projeções futuras (Nunes \& Mello Neto, 2018; Ribeiro \& Mancebo, 2018), saindo de algo positivo (crescimento profissional e pessoal, contribuição sociais e demais) para algo negativo (sofrimento) e/ou instrumental ("trampolim" para algo melhor, sobrevivência).

Rates \& Leda (2018) complementam o que foi dito ao enfatizar que se faz necessário o desenvolvimento de políticas públicas na área da educação que priorizem o docente e a docência, de modo a defender o seu trabalho e a profissão de forma digna, respeitosa e com reconhecimento da sua importância.

Sabe-se e fala-se veladamente na academia sobre saúde mental, precarização do trabalho, competitividade (Rates \& Leda, 2018; Ribeiro \& Leda, 2016), publicar ou perecer, discriminação, assédio (Nunes \& Mello Neto, 2018). No entanto, esses e outros assuntos precisam ser mais debatidos e desenvolvidos para proporcionar ambientes e indivíduos mais saudáveis, pois simplesmente negar a existência de aspectos negativos nesse ambiente altamente turbulento, é negar a si mesmo.

Ademais, é importante e fundamental finalizar esta subseção apresentando uma ideia que é promovida e até naturalizada por muitos docentes e discentes na pós-graduação, que é a aceitação de que ficar "doente" durante o mestrado/doutorado faz parte do processo.

A ideia de que ficar doente é uma coisa normal, e depois você vai poder se reabilitar. A ideia de que se perder a amizade, não tem problema, porque depois você recupera. Então assim, gera uma atmosfera que é assim mesmo, de que não se deve se preocupar, porque depois fica tudo bem. Quando eu comecei com a psicologia, eu vi que não é assim, que não vai ser assim. Porque eu estou me culpando nos dias que eu estou dormindo, que eu estou viajando, que eu estou com minha esposa, que eu estou bebendo com meus amigos, e não tem nada de errado nisso. Não tem absolutamente nada de errado. (E2)

Por fim, pelas verbalizações dos participantes, ficou evidenciada a intensidade em que determinados efeitos se manifestaram. O ambiente da pós-graduação não é completamente saudável, pois apresenta uma carga de trabalho que, muitas vezes, extrapola o necessário, além de ser um ambiente altamente competitivo e de muitos egos inflados. Essa questão, somada ao assédio moral, demonstra a necessidade de criar ações coordenadas para dar suporte tanto aos discentes (elo mais fraco) quanto aos docentes e de disponibilizar canais em que as pessoas possam relatar suas situações de 
modo a cessar essas vivências hostis, além de minimizar as consequências proporcionadas pela ação - transformando esse período de pós-graduação em algo mais saudável. Além disso, não se pode naturalizar as práticas hostis e seus efeitos, pois é preciso agir e prevenir.

\section{Considerações Finais}

Esta pesquisa atendeu ao objetivo de identificar as consequências pelo assédio moral em discentes e docentes vinculados aos Programas de Pós-Graduação stricto sensu em uma Universidade Estadual Brasileira. A metodologia utilizada mostrou-se adequada para a pesquisa e proporcionou resultados consistentes e relevantes. Na pesquisa bibliográfica, identificou-se que esse é um tema importante pela possibilidade de agravos à saúde da população estudada e pelo potencial deletério e de disseminação desse comportamento na academia. Apesar de muitos estudos encontrados na literatura brasileira, o número de respondentes desta pesquisa revela que esse é um assunto teorizado, mas que não tem recebido expressiva adesão para estudos.

A análise de resultados demonstra que o tema ainda é negado e, portanto, não reconhecido pelos docentes e discentes, tendo em vista o número de questionários enviados e as respostas obtidas. O percentual de $65,9 \%$ de respondentes do sexo feminino corrobora os achados de pesquisa (Hirigoyen, 2006), que concluíram ser a mulher mais vulnerável ao assédio. Por suas características intrínsecas e pelo contexto social de contínuas violações de seus direitos, a mulher reconhece com maior prontidão ser vítima de um assédio moral. O percentual de discentes respondentes (mestrandos e doutorandos) foi maior do que o de docentes, conforme mostrou a Tabela 2, o que leva a considerar o silenciamento dos docentes quanto ao assédio moral e a resistência ao sofrimento mental por parte dos discentes. Identificar e expressar as emoções negativas e as angústias diante do quadro de abuso e de violência podem ser entendidos como um ato de resistência e um grito de socorro diante da dominação infringida.

A maioria dos efeitos proporcionados pela vivência de situações de assédio ocorre na sua saúde psíquica (55,7\%), o que significa que a saúde integral do indivíduo está comprometida, assim como sua produtividade laboral e suas relações interpessoais nos grupos aos quais pertence (Barreto, 2000). As emoções negativas experienciadas podem ser maiores do que a satisfação e a realização no trabalho.

A vivência do assédio pode trazer consequências de curto, médio e longo prazo, pois as reações ao sofrimento biopsíquico podem surgir ao longo da vida do sujeito e prejudicar a sua vida laboral, afetiva e pessoal. A fala frequente, mas velada, a respeito do assédio moral na pós-graduação precisa se tornar audível e frequente para que possa haver um acesso maior à informação e à oportunidade de discussões, pois, assim, será possível estabelecer medidas de contenção e de desenvolvimento de estratégias para o enfrentamento do assédio.

A banalização desse problema e a negação de sua existência, assim como dos aspectos negativos nesse ambiente altamente turbulento, se constituem mais uma violência praticada contra os docentes e discentes, com repercussões no significado e no sentido do trabalho acadêmico e, consequentemente, na produtividade. Ribeiro e Leda (2016) ressaltam as arapucas veladas nos discursos produtivistas no trabalho acadêmico, modelo gerencialista importado do setor privado, inserido na cultura da pós-graduação, e que cria barreiras para que o indivíduo consiga agir criticamente. A naturalização do sacrifício de ficar "doente" durante o mestrado/doutorado é uma ideia perversa perpetrada entre os próprios docentes e discentes na propagação dessa cultura de violência.

A Universidade é um importante lócus de saber e de experiências e precisa ampliar a perspectiva de cuidado para com a população, da qual ela faz parte, e fazer jus ao seu papel social dentro de seus muros. É necessário ampliar a perspectiva da visão de seu papel como Promotora de 
Saúde, em que os processos de promoção da saúde sejam contínuos e abranjam todas as áreas da instituição, incluindo docentes, pesquisadores, gestores e demais funcionários, discentes e comunidade local. Além disso, as instalações e a estrutura organizacional devem permear as discussões e intervenções sobre assédio moral, saúde mental e outros temas correlacionados.

Esta pesquisa contribuiu para o conhecimento ao trazer as informações sobre o adoecimento psíquico causado pelo assédio moral na pós-graduação, corroborando outros estudos brasileiros, o que poderá dar força e impulso a ações para enfrentamento desse problema de saúde coletiva. Contribui também para a Ciência em uma visão interdisciplinar sobre o tema.

Para finalizar, sugerem-se novas pesquisas sobre as estratégias de enfrentamento possíveis em uma perspectiva preventiva, de suporte e tratamento, com exemplos de experiências já implementadas em outras universidades.

\section{Referências}

Alcadipani, R., \& Crubellate, J. M. (2003). Cultura organizacional: Generalizações improváveis e conceituações imprecisas. Revista de Administração de Empresas, 43(2), 64-77.

Bardin, L. (2016). Análise de conteúdo (1. ed., rev. e ampl). São Paulo: Edições 70.

Barreto, M. (2000). Uma jornada de humilhações (Dissertação de Mestrado). Pontifícia Universidade Católica de São Paulo, Programa de Pós-Graduação em Psicologia Social, São Paulo.

Barreto, M. (2006). Violência, saúde e trabalho: Uma jornada de humilhações. São Paulo: EDUC.

Barreto, M., \& Venco, S. (2011). Da violência ao suicídio no trabalho. In M. Barreto, N. B. Netto, \& L. B. Pereira (Orgs.). Do assédio moral à morte de si: Significados sociais do suicídio no trabalho (pp. 221-248). 1. ed. São Paulo: Matsunaga.

Brasil. (2012). Resolução n. 466, 12 de dezembro de 2012. Dispõe sobre as diretrizes e as normas regulamentadoras de pesquisa envolvendo seres humanos. Conselho Nacional de Saúde, Brasília.

Caldas, L. C. P. (2007). Assédio moral no trabalho, sofrimento e impactos na familia: Estudo com trabalhadores atendidos no CEST (Centro Especializado em Saúde do Trabalhador), da Prefeitura do Recife/PE (Dissertação de Mestrado). Universidade Católica de Pernambuco, Programa de Pós-Graduação em Psicologia, Recife.

Cassitto, M. G., Fattorini, E., Gilioli, R., Rengo, C., \& Gonik, V. (2003). Sensibilizando sobre el acoso psicológico en el trabajo. Organización Mundial de la Salud Programa de Salud Ocupacional y Ambiental.

Cesar, F. C. R., Sousa, E. T., Ribeiro, L. C. M., \& Oliveira, L. M. A. C. (2018). Graduate school stressors: an integrative literature review. Cogitare Enfermagem, 23(4), 1-11.

Chauí, M. (2016, julho 14). Contra a universidade operacional e a servidão voluntária. Palestra de abertura do Congresso da Universidade Federal da Bahia. Disponível em: http:/ /www.congresso.ufba.br/?p=1658.

Codo, W., Sampaio, J. J., \& Hitomi, A. (1995). Trabalho, indivíduo e sofrimento (2.ed.). Petrópolis: Vozes.

Coutinho, M. C., Magro, M. L. P. D., \& Budde, C. (2011). Entre o prazer e o sofrimento: Um estudo sobre os sentidos do trabalho para professores universitários. Psicologia: teoria e prática, 13(2), 154-167.

Creswell, J. W., \& Clark, V. L. P. (2013). Pesquisa de métodos mistos (2a ed.). Porto Alegre: Penso.

De Souza, M. B. C. A., Cavalcanti, H. T. S., \& Cavalcante, C. E. (2018). Colapso na academia? O comportamento de pós-graduandos em administração e o burnout. Cadernos de Estudos Sociais, 33(1), 59-84.

Dejours, C. (2015). A loucura do trabalho: Estudo de psicopatologia do trabalho (6a ed.). São Paulo: Cortez. 
Einarsen, S., Hoel, H., Zapf, D., \& Cooper, C. L. (2011). The concept of bullying and harassment at work: The European tradition. In S. Einarsen, H. Hoel, D. Zapf, \& C. L. Cooper (Eds.). Bullying and harassment in the workplace: Developments in theory, research, and practice (pp. 3-39). London: Taylor \& Francis.

Fernandes, E. C. (1996). Qualidade de vida no trabalho: Como medir para melhorar. Salvador: Casa da Qualidade.

Freitas, M. E., Heloani, R., \& Barreto, M. (2008). Assédio moral no trabalho. São Paulo: Cengage Learning.

Garcia, A. L., Oliveira, E. R. A., \& Barros, E. B. (2008). Qualidade de vida de professores do ensino superior na área da saúde: Discurso e prática cotidiana. Cogitare Enfermagem, 13(1), 1-15.

Gasparini, S. M., Barreto, S. M., \& Assunção, A. Á. (2005). O professor, as condições de trabalho e os efeitos sobre sua saúde. Educação e Pesquisa, 31(2), 189-199.

Heloani, R., \& Barreto, M. (2015). Assédio moral nas relações sociais no âmbito das instituições públicas. In E. F. Silva, F. Zanin, J. A. P Gediel, \& L. E. de Mello (Orgs.). Estado, poder e assédio: Relações de trabalbo na administração pública (pp. 145-162). Curitiba: Kairós Edições.

Heloani, R., \& Barreto, M. (2018). Assédio moral: Gestão por bumilhação. Curitiba, Juruá.

Hirigoyen, M-F. (2006). Mal-estar no trabalho: Redefinindo o assédio moral (3a ed.). Rio de Janeiro: Bertrand Brasil.

Hirigoyen, M-F. (2008). Assédio moral: A violência perversa no cotidiano (10a ed.). Rio de Janeiro: Bertrand Brasil.

Hoel, H., Sparks, K., \& Cooper, C. L. (2001). The cost of violence/stress at work and the benefits of a violence/stress-free working environment. Geneva: International Labour Organisation (ILO).

Keashly, L., \& Jagatic, K. (2003). By any other name: American perspectives on workplace bullying. In S. Einarsen, H. Hoel, D. Zapf, \& C. L. Cooper (Eds.). Bullying and emotional abuse in the workplace: International perspectives in research and practice (pp. 31-61). London: Taylor \& Francis.

Lancman, S., \& Sznelwar, L. I. (2011). Christophe Dejours: Da psicopatologia à psicodinâmica do trabalho. Rio de Janeiro: Fio Cruz.

Lautert, L. (1995). O desgaste profissional do enfermeiro. Revista Gaúcha de Enfermagem, 16(1/2), 98100.

Levecque, K., Anseel, A., Beuckelaer, A., Heyden, J. V. d., \& Gislef, L. (2017). Work organization and mental health problems in PhD students. Research Policy, 46(4), 868-879.

Lima, M. F. E. M., \& Lima-Filho, D. O. (2009). Condições de trabalho e saúde do/a professor/a universitário/a. Ciências \& Cognição, 14(3), 62-82.

Maissiat, G. S., Lautert, L., Pai, D. D., \& Tavares, J. P. (2015). Contexto de trabalho, prazer e sofrimento na atenção básica em saúde. Revista Gaúcha de Enfermagem, 36(2), 42-49.

Mancebo, D., \& Rocha, M. L. (2002). Avaliação na educação superior e trabalho docente. Interações, 7(13), 55-75.

Marquese, E. C., \& Moreno, C. R. C. (2009). Satisfação no trabalho e capacidade para o trabalho entre docentes universitários. Psicologia em Estudo, 14(1), 75-82.

Meneghini, F., Paz, A. A., \& Lautert, T. (2011). Fatores ocupacionais associados aos componentes da Síndrome de Burnout. Texto Contexto Enferm, 20(2), 225-33.

Merlo, A. R. C., Bottega, C. G., \& Perez, K. V. (2014). Atenção ao sofrimento e ao adoecimento psíquico do trabalhador e da trabalhadora: Cartilha para profissionais do Sistema Único de Saúde-SUS. Porto Alegre: Evangraf.

Minayo, M. C. S. (1994). Pesquisa social: Teoria, método e criatividade. Rio de Janeiro: Vozes. 
Nielsen, M. B., \& Einarsen, S. V. (2018). What we know, what we do not know, and what we should and could have known about workplace bullying: An overview of the literature and agenda for future research. Aggression and Violent Behavior, 42, 71-83.

Nunes, T. S. (2016). A influência da cultura organizacional na ocorrência do assédio moral no trabalho na Universidade Federal de Santa Catarina (Tese de Doutorado). Universidade Federal de Santa Catarina, Centro Socioeconômico, Programa de Pós-Graduação em Administração, Florianópolis.

Nunes, T. S. (2018). Os elementos presentes na cultura e práticas da Pós-Graduação que influenciam a ocorrência do assédio moral. In Anais, XXI Seminários em Administração - SEMEAD (pp. 115). São Paulo, SP.

Nunes, T. S., \& Mello Neto, G. A. R. (2018). Assédio moral na pós-graduação: Do abuso de poder à recusa a diferença. In Anais, XLII Encontro da $A N P A D$ - EnANP $A D$ (pp. 1-16). Curitiba, PR.

Nunes, T. S., \& Tolfo, S. R. (2012). Assédio moral no trabalho: Consequências identificadas por servidores docentes e técnico-administrativos em uma universidade federal brasileira. Revista Gestão Universitária na América Latina - GUAL, 5(3), 264-286.

Nunes, T. S., Tolfo, S. R., \& Espinosa, L. M. C. (2018). Assédio moral no trabalho: A compreensão dos trabalhadores sobre a violência. Revista de Gestão e Secretariado, 9(2), 205-219.

Pellegrini, P. G. (2016). Assédio moral no trabalho e repercussões na estrutura e dinâmica familiares (Dissertação de Mestrado). Universidade Federal de Santa Catarina, Centro de Filosofia e Ciências Humanas. Programa de Pós-Graduação em Psicologia, Florianópolis.7

Rates, A. C. F., \& Leda, D. B. (2018). "Pau pra toda obra": As vivências de prazer e sofrimento no trabalho de professores substitutos de uma Universidade Federal. Revista Trabalho (En)Cena, 3(3), 34-56.

Ribeiro, C. V. S., \& Leda, D. B. (2016). O trabalho docente no enfrentamento do gerencialismo nas Universidades Federais brasileiras: Repercussões na subjetividade. Educação em Revista, 32(4), 97-117.

Ribeiro, C. V. S., \& Mancebo, D. (2013). O servidor público no mundo do trabalho do século XXI. Psicologia: Ciência e Profissão, 33(1), 192-207.

Silva, E. P., Heloani, J. R., \& Piolli, E. (2012). Autonomia controlada e adoecimento do professor. Revista Educação e Políticas em Debate, 2(2), 370-383.

Tolfo, S. R., Silva, N., \& Krawulski, E. (2015). Assédio moral no trabalho: Interface com a cultura organizacional e a gestão de pessoas em organizações públicas. In M. L. Emmendoerfer, S. R. Tolfo, \& T. S. Nunes (Orgs.). Assédio moral: Em organizações públicas e a (re)ação dos sindicatos (pp. 99-117). Curitiba, PR: ed. CRV.

Trindade, N; Bonito, J. (2011). O adoecimento do trabalhador docente do ciclo básico I e II da escola pública municipal de Belém no distrito administrativo do entroncamento. In Anais, I Congresso Nacional de Comportamentos de Saúde Infanto-Juvenis, Viseu, Portugal.

Yung, R. W. (2011). Assédio Moral no Trabalho, suas formas de expressão e as repercussões nas diversas esferas da vida. (Dissertação de Mestrado). Universidade do Vale do Itajaí, Programa de Mestrado Profissional em Saúde e Gestão do Trabalho, Itajaí. 


\section{Sobre os Autores}

Thiago Soares Nunes

Centro Universitário Una

adm.thiagosn@gmail.com

ORCID: http://orcid.org/0000-0002-1323-8160

Professor do Mestrado Profissional em Administração do Centro Universitário Una. Pós-

Doutorado em Administração pela Universidade Estadual de Maringá. Doutor em

Administração pela Universidade Federal de Santa Catarina (UFSC), com período sanduíche no Departamento de Psicologia Social da Universidade Autônoma de Barcelona (UAB/Espanha). Mestre e Graduado em Administração pela UFSC.

\section{Eliana Marcia Martins Fittipaldi Torga}

Centro Universitário Una

elianatorga@gmail.com

ORCID: http://orcid.org/0000-0003-4175-9390

Doutora e Mestre em Administração pela Faculdade de Ciências Econômicas da Universidade Federal de Minas Gerais, graduação em Psicologia - Instituto Cultural Newton de Paiva Ferreira. Pós-graduada em Psicologia Hospitalar e Intervenção em Emergências em Sevilha, Espanha. Professora Adjunta do Centro Universitário Una. Docente do Programa de Mestrado Profissional em Administração.

\section{Sobre as Editoras Convidas}

\section{Deise Mancebo}

Universidade do Estado do Rio de Janeiro

deise.mancebo@gmail.com

http://orcid.org/0000-0001-8312-4495

Doutora em Educação pela Pontifícia Universidade Católica de São Paulo. Professora Titular da Universidade do Estado do Rio de Janeiro. Pesquisadora e professora do Programa de Pósgraduação em Políticas Públicas e Formação Humana. Coordenadora da Rede Universitas/Br.

\section{Kátia Maria Teixeira Santorum}

Universidade do Estado do Rio de Janeiro

katia.santorum@gmail.com

https://orcid.org/0000-0003-2830-157X

Doutora em Saúde Pública pela Escola Nacional de Saúde Pública Sérgio Arouca / Fundação

Oswaldo Cruz (Fiocruz). Professora Adjunta da Universidade do Estado do Rio de

Janeiro. Pesquisadora e professora do Programa de Pós-graduação em Políticas Públicas e Formação Humana.

\section{Carla Vaz dos Santos Ribeiro}

Universidade Federal do Maranhão

carlavazufma@gmail.com

http://orcid.org/0000-0002-5518-9619 
Doutora em Psicologia Social pela Universidade do Estado do Rio de Janeiro. Professora Associada da Universidade Federal do Maranhão. Pesquisadora e professora do Programa de Pós-graduação em Psicologia da UFMA. Integrante da Rede Universitas/Br.

\section{Denise Bessa Léda}

Universidade Federal do Maranhão

denise.bessa.leda@gmail.com

http://orcid.org/0000-0002-8696-6126

Doutora em Psicologia Social pela Universidade do Estado do Rio de Janeiro. Professora da Universidade Federal do Maranhão. Professora permanente e pesquisadora do Programa de PósGraduação em Psicologia da Universidade Federal do Maranhão. Membro da Rede Universitas/Br e do Grupo de Pesquisa Psicodinâmica e Clínica do Trabalho da Associação Nacional de Pesquisa e Pós-graduação em Psicologia.

\section{Dossiê Especial
O Trabalho no Ensino Superior arquivos analíticos de políticas educativas}

Volume 28 Número 11
20 de janeiro 2020

\section{(c) (†) (2)}

Los/as lectores/as pueden copiar, mostrar, distribuir, y adaptar este articulo, siempre y cuando se de crédito y atribución al autor/es y a Archivos Analíticos de Políticas Educativas, los cambios se identifican y la misma licencia se aplica al trabajo derivada. Más detalles de la licencia de Creative Commons se encuentran en https://creativecommons.org/licenses/bysa/2.0/. Cualquier otro uso debe ser aprobado en conjunto por el autor/es, o AAPE/EPAA. La sección en español para Sud América de AAPE/EPAA es publicada por el Mary Lou Fulton Teachers College, Arizona State University y la Universidad de San Andrés de Argentina. Los artículos que aparecen en AAPE son indexados en CIRC (Clasificación Integrada de Revistas Científicas, España) DIALNET (España), Directory of Open Access Journals, EBSCO Education Research Complete, ERIC, Education Full Text (H.W. Wilson), PubMed, QUALIS A1 (Brazil), Redalyc, SCImago Journal Rank, SCOPUS, SOCOLAR (China).

Por errores y sugerencias contacte a Fischman@asu.edu

Síganos en EPAA's Facebook comunidad at https://www.facebook.com/EPAAAAPE y en Twitter feed@epaa_aape. 


\section{arquivos analíticos de políticas educativas conselho editorial}

Editor Consultor: Gustavo E. Fischman (Arizona State University)

Editoras Associadas: Andréa Barbosa Gouveia (Universidade Federal do Paraná), Kaizo Iwakami Beltrao, (Brazilian School of Public and Private Management - EBAPE/FGVl), Sheizi Calheira de Freitas (Federal University of Bahia), Maria Margarida Machado, (Federal University of Goiás / Universidade Federal de Goiás), Gilberto José Miranda, (Universidade Federal de Uberlândia, Brazil), Marcia Pletsch, Sandra Regina Sales (Universidade Federal Rural do Rio de Janeiro)

\author{
Almerindo Afonso \\ Universidade do Minho \\ Portugal
}

Rosanna Maria Barros Sá

Universidade do Algarve

Portugal

\section{Maria Helena Bonilla \\ Universidade Federal da Bahia \\ Brasil}

Rosa Maria Bueno Fischer Universidade Federal do Rio

Grande do Sul, Brasil

Alice Casimiro Lopes

Universidade do Estado do Rio de

Janeiro, Brasil

\section{Suzana Feldens Schwertner Centro Universitário Univates Brasil}

Geovana Mendonça Lunardi Mendes Universidade do Estado de Santa Catarina

Flávia Miller Naethe Motta

Universidade Federal Rural do Rio de Janeiro, Brasil

Alexandre Fernandez Vaz

Universidade Federal de Santa

Catarina, Brasil

Regina Célia Linhares Hostins

Universidade do Vale do Itajaí,

Brasil

\section{Alfredo Macedo Gomes \\ Universidade Federal de \\ Pernambuco Brasil}

Jefferson Mainardes

Universidade Estadual de Ponta

Grossa, Brasil

Jader Janer Moreira Lopes

Universidade Federal Fluminense

e Universidade Federal de Juiz de Fora, Brasil

\section{Debora Nunes \\ Universidade Federal do Rio \\ Grande do Norte, Brasil}

Alda Junqueira Marin

Pontifícia Universidade Católica de São Paulo, Brasil

Dalila Andrade Oliveira

Universidade Federal de Minas

Gerais, Brasil
José Augusto Pacheco

Universidade do Minho, Portugal

Jane Paiva

Universidade do Estado do Rio de Janeiro, Brasil

Paulo Alberto Santos Vieira Universidade do Estado de Mato Grosso, Brasil

Fabiany de Cássia Tavares Silva Universidade Federal do Mato Grosso do Sul, Brasil

\section{António Teodoro}

Universidade Lusófona

Portugal

\section{Lílian do Valle}

Universidade do Estado do Rio de Janeiro, Brasil

\author{
Alfredo Veiga-Neto \\ Universidade Federal do Rio \\ Grande do Sul, Brasil
}




\section{archivos analíticos de políticas educativas consejo editorial}

Editor Consultor: Gustavo E. Fischman (Arizona State University)

Editores Asociados: Felicitas Acosta (Universidad Nacional de General Sarmiento, Argentina), Armando Alcántara Santuario (Universidad Nacional Autónoma de México), Ignacio Barrenechea, Jason Beech (Universidad de San Andrés), Angelica Buendia, (Metropolitan Autonomous University), Alejandra Falabella (Universidad Alberto Hurtado, Chile), Carolina Guzmán-Valenzuela (University of Chile), Veronica Gottau (Universidad Torcuato Di

Tella), Antonio Luzon, (Universidad de Granada), José Luis Ramírez, (Universidad de Sonora), Paula Razquin, Axel

Rivas (Universidad de San Andrés), Maria Veronica Santelices (Pontificia Universidad Católica de Chile), Maria Alejandra Tejada-Gómez (Pontificia Universidad Javeriana, Colombia)

Claudio Almonacid

Universidad Metropolitana de

Ciencias de la Educación, Chile

Miguel Ángel Arias Ortega

Universidad Autónoma de la

Ciudad de México

Xavier Besalú Costa

Universitat de Girona, España

Xavier Bonal Sarro Universidad

Autónoma de Barcelona, España

Antonio Bolívar Boitia

Universidad de Granada, España

José Joaquín Brunner Universidad Diego Portales, Chile

Damián Canales Sánchez

Instituto Nacional para la

Evaluación de la Educación, México

Gabriela de la Cruz Flores

Universidad Nacional Autónoma de México

Marco Antonio Delgado Fuentes

Universidad Iberoamericana,

México

Inés Dussel, DIE-CINVESTAV, México

Pedro Flores Crespo Universidad Iberoamericana, México

\author{
Ana María García de Fanelli \\ Centro de Estudios de Estado y \\ Sociedad (CEDES) CONICET, \\ Argentina \\ Juan Carlos González Faraco \\ Universidad de Huelva, España \\ María Clemente Linuesa \\ Universidad de Salamanca, España \\ Jaume Martínez Bonafé \\ Universitat de València, España
}

Alejandro Márquez Jiménez

Instituto de Investigaciones sobre la Universidad y la Educación, UNAM, México

María Guadalupe Olivier Tellez, Universidad Pedagógica Nacional, México

Miguel Pereyra Universidad de Granada, España

Mónica Pini Universidad Nacional de San Martín, Argentina

Omar Orlando Pulido Chaves

Instituto para la Investigación Educativa y el Desarrollo Pedagógico (IDEP)

José Ignacio Rivas Flores

Universidad de Málaga, España

\section{Miriam Rodríguez Vargas \\ Universidad Autónoma de \\ Tamaulipas, México}

José Gregorio Rodríguez

Universidad Nacional de Colombia, Colombia

Mario Rueda Beltrán Instituto de Investigaciones sobre la Universidad y la Educación, UNAM, México

José Luis San Fabián Maroto Universidad de Oviedo, España

Jurjo Torres Santomé, Universidad de la Coruña, España

Yengny Marisol Silva Laya

Universidad Iberoamericana, México

Ernesto Treviño Ronzón

Universidad Veracruzana, México

Ernesto Treviño Villarreal Universidad Diego Portales Santiago, Chile

Antoni Verger Planells Universidad Autónoma de Barcelona, España

Catalina Wainerman

Universidad de San Andrés, Argentina

Juan Carlos Yáñez Velazco Universidad de Colima, México 


\section{education policy analysis archives editorial board}

Lead Editor: Audrey Amrein-Beardsley

Editor Consultor: Gustavo E. Fischman (Arizona State University)

Associate Editors: Melanie Bertrand, David Carlson, Lauren Harris, Eugene Judson, Mirka Koro-Ljungberg, Daniel Liou, Scott Marley, Molly Ott, Iveta Silova (Arizona State University)

Cristina Alfaro

San Diego State University

Gary Anderson

New York University

Michael W. Apple

University of Wisconsin, Madison

Jeff Bale

University of Toronto, Canada

Aaron Bevanot SUNY Albany

David C. Berliner

Arizona State University

Henry Braun Boston College

\section{Casey Cobb}

University of Connecticut

Arnold Danzig

San Jose State University

Linda Darling-Hammond

Stanford University

Elizabeth H. DeBray

University of Georgia

David E. DeMatthews

University of Texas at Austin

Chad d'Entremont Rennie Center

for Education Research \& Policy

John Diamond

University of Wisconsin, Madison

Matthew Di Carlo

Albert Shanker Institute

Sherman Dorn

Arizona State University

Michael J. Dumas

University of California, Berkeley

Kathy Escamilla

University ofColorado, Boulder

Yariv Feniger Ben-Gurion

University of the Negev

Melissa Lynn Freeman

Adams State College

Rachael Gabriel

University of Connecticut
Amy Garrett Dikkers University

of North Carolina, Wilmington

Gene V Glass

Arizona State University

Ronald Glass University of

California, Santa Cruz

Jacob P. K. Gross

University of Louisville

Eric M. Haas WestEd

Julian Vasquez Heilig California

State University, Sacramento

Kimberly Kappler Hewitt

University of North Carolina

Greensboro

Aimee Howley Ohio University

Steve Klees University of Maryland

Jaekyung Lee SUNY Buffalo

Jessica Nina Lester

Indiana University

Amanda E. Lewis University of

Illinois, Chicago

Chad R. Lochmiller Indiana

University

Christopher Lubienski Indiana

University

Sarah Lubienski Indiana University

William J. Mathis

University of Colorado, Boulder

Michele S. Moses

University of Colorado, Boulder

Julianne Moss

Deakin University, Australia

Sharon Nichols

University of Texas, San Antonio

Eric Parsons

University of Missouri-Columbia

Amanda U. Potterton

University of Kentucky

Susan L. Robertson

Bristol University
Gloria M. Rodriguez

University of California, Davis

R. Anthony Rolle

University of Houston

A. G. Rud

Washington State University

Patricia Sánchez University of

University of Texas, San Antonio

Janelle Scott University of

California, Berkeley

Jack Schneider University of

Massachusetts Lowell

Noah Sobe Loyola University

Nelly P. Stromquist

University of Maryland

Benjamin Superfine

University of Illinois, Chicago

Adai Tefera

Virginia Commonwealth University

A. Chris Torres

Michigan State University

Tina Trujillo

University of California, Berkeley

Federico R. Waitoller

University of Illinois, Chicago

Larisa Warhol

University of Connecticut

John Weathers University of

Colorado, Colorado Springs

Kevin Welner

University of Colorado, Boulder

Terrence G. Wiley

Center for Applied Linguistics

John Willinsky

Stanford University

Jennifer R. Wolgemuth

University of South Florida

Kyo Yamashiro

Claremont Graduate University

Miri Yemini

Tel Aviv University, Israel 